\title{
LEAGUE-LEVEL ATTENDANCE AND OUTCOME UNCERTAINTY IN U.S. PRO SPORTS LEAGUES
}

\author{
BRIAN MILLS and RODNEY FORT*
}

\begin{abstract}
We extend the breakpoint literature regarding annual league-level attendance and the impact of outcome uncertainty to the National Basketball Association, National Football League, and National Hockey League. As our measures are different than past work on baseball, we also apply our model to the American and National Leagues. Attendance series for each league under consideration are not stationary overall, but are stationary with break points. No form of outcome uncertainty (game, playoff, or across seasons) matters for attendance in hockey or baseball regardless of which game uncertainty variable is used. Under the measure of game uncertainty that recommends itself for football, only play-off uncertainty matters for attendance. Whether outcome uncertainty matters for basketball depends on the measure of game uncertainty. Situational similarities in the break points across leagues suggest general areas for future research. (JEL L83, C22)
\end{abstract}

\section{INTRODUCTION}

Past empirical work investigating what has come to be called Simon Rottenberg's (1956) "uncertainty of outcome hypothesis" (henceforth, UOH) for North American professional sports leagues has overwhelmingly involved analysis of Major League Baseball (MLB) attendance. ${ }^{1}$ What there are on attendance demand studies of other North American sports leagues

*We would like to thank Professors Junsoo Lee and Mark Strazicich and Pierre Perron and Jushan Bai for making their unit-root and breakpoint estimation codes publicly available, respectively. Finally, we would like to thank the anonymous reviewers that improved this work immensely.

Mills: Assistant Professor, Department of Tourism, Recreation and Sport Management, University of Florida, Gainesville, FL 32611-8200. Phone 352-294-1664, E-mail bmmillsy@hhp.ufl.edu

Fort: Professor, Department of Sports Management, University of Michigan, Ann Arbor, MI 48109-2808. Phone 734-647-8989, Fax 734-647-2808, E-mail rodfort@umich.edu

1. Baade and Tiehen (1990); Bruggink and Eaton (1996); Butler (2002); Coates and Harrison (2005); Coffin (1996); Demmert (1973); Domazlicky and Kerr (1990); Gitter and Rhoads (2010) (MiLB); Kahane and Shmanske (1997); Knowles and Sherony (1992); Krautmann, Lee, and Quinn (2011); Lee (2009); Lee and Fort (2008); Lemke, Leonard, and Tlhokwane (2007); Meehan, Nelson, and Richardson (2007); Noll (1974); Rascher and Solmes (2007); Schmidt and Berri (2001, 2002, 2004); Siegfried and Eisenberg, (1980) (MiLB); Soebbing (2008); Tainsky and Winfree (2010a, 2010b); Winfree et al. (2004). have focused on fan substitution, stadium honeymoon effects, discrimination, and impacts of labor disputes. ${ }^{2}$ At best, as detailed shortly, this literature treats the $\mathrm{UOH}$ inconsistently.

This paper shifts focus to the neglected National Basketball Association (NBA), National Football League (NFL), and National Hockey League (NHL) with a full time series assessment

2. Coates and Humphreys (2007); Jones and Ferguson (1988); Leadley and Zygmont (2006); Paul (2003); Paul and Weinbach (2007); Pivovarnik et al. (2008); Schmidt and Berri (2004); Winfree and Fort (2008).

\section{ABBREVIATIONS}

ADF: Augmented Dickey-Fuller

AL: American League

CSU: Consecutive Season Uncertainty

DFGLS: Generalized Least Squares Dickey-Fuller Test GU: Game Uncertainty

HICB: Herfindahl Index of Competitive Balance

LAPG: Annual, League-Level, per Game Attendance

MLB: Major League Baseball

NBA: National Basketball Association

NFL: National Football League

NHL: National Hockey League

NL: National League

PP: Phillips-Perron

PU: Play-off Uncertainty

RSD: Ratio of Standard Deviations

TL: Tail Likelihood

UOH: Uncertainty of Outcome Hypothesis 
of the impact of outcome uncertainty on leaguelevel annual attendance (while maintaining comparisons with MLB). The main contributions of the paper are two. First, unlike any of the work just cited, we assess the impact of all three main types of outcome uncertainty in these three leagues, simultaneously-game uncertainty (GU), play-off uncertainty (PU), and consecutive season uncertainty (CSU). ${ }^{3}$ Overall, empirical results on the influence of the $\mathrm{UOH}$ have been mixed. Szymanski (2003) reviews the findings of a number of studies and concludes that the UOH does not have any consistent (emphasis added) empirical backing. Borland and MacDonald (2003) offered a more nuanced take on the issue, surmising that a winning probability closer to 60\%-70\% maximized attendance, rather than 50\%. ${ }^{4}$ However, Fort and Lee (2006) note that the weak and inconsistent treatment of the UOH as well as complete inattention to time series issues may be at the root of this inconsistency in outcomes. Joining Lee and Fort (2008) on MLB, this paper addresses this issue by incorporating all three main types of outcome uncertainty in a time series framework for the rest of the North American major leagues.

Second, we investigate a variety of measures of outcome uncertainty offered in the literature, finding that results are a bit sensitive to the choice of GU measures. While we choose a particular GU measure for the sake of comparison among the NBA, NFL, and NHL, we also make clear what the differences are if other measures are used. The use of GU in previous time series work on MLB by Lee and Fort (2008) also informs our choice. In addition, we are able to contrast their choice with ours concerning the measurement of PU for MLB.

The work here, by its aggregate league-level nature, is complementary to cross-section/time series analysis. First, most generally, aggregate league-level time series is only one possible choice about the unit of observation for analyzing the impact of competitive balance on attendance. Thus, it will be complementary to work at less aggregated levels of attendance. Second,

3. Rottenberg never really addressed CSU in his original work, but we estimate its importance because it is either assumed in some earlier work (Hadley, Cieka, and Krautmann 2005; Humphreys 2002) or there is professional interest in fan response to dynasties (Krautmann and Hadley 2006, and references therein).

4. More recent investigations are also mixed on the UOH matters (Lee and Fort 2008; Meehan, Nelson, and Richardson 2007; Rascher and Solmes 2007; Soebbing 2008). the actual break points identified in our work suggest additional research questions that may best be addressed using less aggregated data, for example, with cross-section/time series data on attendance, perhaps even at the individual team level.

The work here is also of aid to future cross-section/time series endeavors. Nonstationary data can adversely affect coefficient standard error estimates and produce spurious correlations (Davies, Downward, and Jackson 1995; Dobson and Goddard 2001). As also detailed in Davis (2008), ascertaining that regression analyses are performed on stationary subsets of data ensures that valid inferences can be made from regression coefficients. Our work identifies stationary subsets of the data to help overcome this problem. While a first-differences treatment of nonstationary time series does not allow the calculation of direct elasticity estimates for variables within a regression, our work allows estimation without first differences, and elasticity interpretations are appropriate.

By way of preview, the attendance data in all three leagues are nonstationary, but stationary with break points. Also, we find very limited support for the $\mathrm{UOH}$ and, upon reflection on the choice of measures for GU, suggest that the previous Lee and Fort (2008) finding that PU matters for MLB is sensitive to the choice of measurement. By our measures, for the NHL, and for the National League (NL) and American League (AL) in MLB, the $\mathrm{UOH}$ is rejected for all three types of outcome uncertainty regardless of which measure is used for GU. A particular measure of GU recommends itself for the NFL with the result that the UOH matters for PU in that league. Whether GU matters or not for the NBA is a matter of which GU variable is used. However, while outcome uncertainty measures do produce some statistically significant results for Rottenberg's UOH for the NBA and the NFL, the economic impacts are trivial for league revenues. Finally, there are situational similarities among some of the break points across the different leagues, suggesting that further analysis of the impacts of global conflict, league expansion, league responses to rival leagues (e.g., mergers), and fan substitution among pro-sports leagues during strikes and lockouts will prove insightful.

This paper proceeds as follows. In Section II, we present data collection methods, our selection of measures for the three types of outcome uncertainty, data issues, and our methodology. 
Section III presents our results organized around the four main points of analysis - unit-root tests of stationarity for each league (including unit root with break points), variable selection for $\mathrm{GU}$, the break points for each league, and the results for outcome uncertainty on attendance. A comparison of situational similarities associated with break points across the leagues as a guide to future general research areas is in Section IV. Finally, in Section V, we conclude with remaining suggestions for future research.

\section{DATA, MEASUREMENT, AND METHODOLOGY}

\section{A. Data}

Our data come from Rod's Sports Business Data (2012a, 2012b, 2012c) and the Sports Reference league-specific coverage websites (Basketball-Reference 2012; HockeyReference 2012; Pro-Football-Reference 2012). ${ }^{5}$ As in all of the past works on aggregate league attendance already cited, we specify attendance as annual, league-level, per-game attendance (LAPG) because the number of games and teams has changed substantially throughout the history of each respective league. LAPG is calculated by dividing annual total league attendance by the total number of games played for each year within the series. The length of LAPG series in each league is subject to the availability of attendance data-NBA: 1955-1956 through 2009-2010; NFL: 1934 through 2009; NHL: 1960-1961 through 2009-2010. We stress that we do not formally analyze demand, as the models do not account for sellouts, especially apparent for the NFL. In addition, many of the usual variables of interest in demand analysis are subsumed in trend variables due to lack of data. Cross-section/time series approaches where more data are available will prove enlightening.

\section{B. Measurement}

We investigated various measures of outcome uncertainty already available in the literature in order to preserve some comparability for our

5. There is some disagreement of available data sources for NHL attendance in certain years. For that league only, we average three sources of game attendance for years in which multiple estimates are available-Rod's Sports Business Data (2012), Hockey Zone Plus (2010), and Andrew's Dallas Stars Page (2010) eventual estimation results. ${ }^{6}$ The variables, their definitions, and their descriptive statistics are in Table $1 .^{7}$ Published measures of GU capture two possible dimensions of fan preference, the overall distribution of winning percentage outcomes and just the tails of that distribution. The Ratio of Standard Deviations (RSD; Fort and Quirk 1995; Noll 1988; Scully 1989) and exposition of the Herfindahl Index of Competitive Balance (HICB) by Lenten (2009) both measure the breadth of the entire distribution of winning percentages. The Tail Likelihood measure (TL, Fort and Quirk 1995) used in Lee and Fort (2008) examines both tails of the distribution of winning percentages. Since there is no overwhelming evidence that either of these dimensions is more important to fans of any particular league, we investigate all of these GU measures further, in the results section. ${ }^{8}$

For PU and CSU, we were able to compare the published options and choose based on how measurements adhere to the relevant task. For PU, we are convinced that the PLU measure from Krautmann, Lee, and Quinn (2011) is superior due to its robustness with respect to the distribution of play-off contending teams. ${ }^{9}$ PLU contains information about the entire distribution of team distance from first place while the other published measure (Lee and Fort 2008) contained only information about the first and second place finish.

There also are two extant measures for CSU, the correlation in team performance across seasons (CORR) in Lee and Fort (2008), based on the measure in Butler (1995), and Lenten's (2009) "mobility gain function." We believe that CORR is defensible by its "longer memory" with three prior seasons compared with Lenten's

6. We thank an anonymous referee and the editor for instructing us to undertake the investigation of different measures of outcome uncertainty. Our original choice was to use the same measures as in Lee and Fort (2008) in order to maintain comparability to that earlier work. However, as the referee put it, without an investigation of different measures, any statement about the $\mathrm{UOH}$ and attendance may have more to say about the measures chosen than about Rottenberg's idea.

7. Decade averages are used for exposition in Table 1. For the NBA, the 1950s LAPG average uses only data from 1955-1956 through the 1959-1960 seasons, because of availability. However, all uncertainty measures use all seasons in each decade included in the table.

8. The NHL uses a point system rather than simple winning percentages. We convert the NHL to winning percentage, recognizing that for our purposes the damage is light. On this issue, see Fort (2007) and Owen (2012).

9. We thank the anonymous referee who first pointed out this important distinction. 
TABLE 1

LAPG, Outcome Uncertainty Measures, and Decade Averages

\begin{tabular}{|c|c|c|c|c|c|c|c|c|c|}
\hline NBA & LAPG & GU & PU & CSU & $\mathbf{A L}$ & LAPG & GU & PU & $\mathrm{CSU}$ \\
\hline $1950 \mathrm{~s}$ & 4,778 & 0.241 & 0.060 & 0.410 & $1900 \mathrm{~s}$ & 4,809 & 0.038 & 0.020 & 0.499 \\
\hline $1960 \mathrm{~s}$ & 5,714 & 0.022 & 0.052 & 0.558 & $1910 \mathrm{~s}$ & 4,997 & 0.045 & 0.015 & 0.458 \\
\hline $1970 \mathrm{~s}$ & 9,644 & 0.201 & 0.047 & 0.285 & $1920 \mathrm{~s}$ & 7,796 & 0.064 & 0.015 & 0.628 \\
\hline $1980 \mathrm{~s}$ & 12,110 & 0.052 & 0.052 & 0.654 & $1930 \mathrm{~s}$ & 6,445 & 0.018 & 0.011 & 0.747 \\
\hline $1990 \mathrm{~s}$ & 15,836 & 0.044 & 0.047 & 0.605 & $1940 \mathrm{~s}$ & 11,235 & 0.103 & 0.017 & 0.616 \\
\hline $2000 \mathrm{~s}$ & 17,204 & 0.105 & 0.046 & 0.488 & $1950 \mathrm{~s}$ & 13,360 & 0.055 & 0.015 & 0.742 \\
\hline \multirow[t]{2}{*}{ Avg. } & 11,436 & 0.112 & 0.050 & 0.501 & $1960 \mathrm{~s}$ & 12,606 & 0.166 & 0.014 & 0.638 \\
\hline & & & & & $1970 \mathrm{~s}$ & 14,824 & 0.267 & 0.021 & 0.558 \\
\hline NFL & LAPG & GU & PU & CSU & $1980 \mathrm{~s}$ & 22,100 & 0.364 & 0.024 & 0.433 \\
\hline $1930 \mathrm{~s}$ & 18,205 & 0.189 & 0.046 & 0.647 & $1990 \mathrm{~s}$ & 27,906 & 0.395 & 0.026 & 0.337 \\
\hline $1940 \mathrm{~s}$ & 26,521 & 0.167 & 0.043 & 0.483 & $2000 \mathrm{~s}$ & 29,160 & 0.167 & 0.029 & 0.560 \\
\hline $1950 \mathrm{~s}$ & 31,211 & 0.495 & 0.048 & 0.382 & Avg. & 14,198 & 0.154 & 0.019 & 0.568 \\
\hline $1960 \mathrm{~s}$ & 44,349 & 0.470 & 0.046 & 0.428 & & & & & \\
\hline $1970 \mathrm{~s}$ & 54,326 & 0.862 & 0.051 & 0.518 & NL & LAPG & GU & PU & CSU \\
\hline $1980 \mathrm{~s}$ & 54,048 & 1.363 & 0.059 & 0.357 & $1900 \mathrm{~s}$ & 4,366 & 0.006 & 0.012 & 0.690 \\
\hline $1990 \mathrm{~s}$ & 57,732 & 1.041 & 0.061 & 0.354 & $1910 \mathrm{~s}$ & 4,203 & 0.101 & 0.012 & 0.396 \\
\hline $2000 s$ & 64,478 & 0.998 & 0.059 & 0.345 & $1920 \mathrm{~s}$ & 7,248 & 0.090 & 0.020 & 0.690 \\
\hline \multirow[t]{2}{*}{ Avg. } & 47,432 & 0.725 & 0.052 & 0.428 & $1930 \mathrm{~s}$ & 6,686 & 0.072 & 0.020 & 0.685 \\
\hline & & & & & $1940 \mathrm{~s}$ & 10,478 & 0.047 & 0.015 & 0.631 \\
\hline NHL & LAPG & GU & PU & CSU & $1950 \mathrm{~s}$ & 13,348 & 0.146 & 0.017 & 0.693 \\
\hline 1960s & 12,658 & 0.174 & 0.051 & 0.527 & $1960 \mathrm{~s}$ & 15,578 & 0.148 & 0.019 & 0.494 \\
\hline $1970 \mathrm{~s}$ & 12,837 & 0.081 & 0.050 & 0.762 & $1970 \mathrm{~s}$ & 18,215 & 0.294 & 0.022 & 0.603 \\
\hline $1980 \mathrm{~s}$ & 13,842 & 0.521 & 0.058 & 0.631 & $1980 \mathrm{~s}$ & 23,191 & 0.393 & 0.024 & 0.298 \\
\hline $1990 \mathrm{~s}$ & 15,539 & 0.647 & 0.057 & 0.483 & $1990 \mathrm{~s}$ & 28,016 & 0.339 & 0.026 & 0.178 \\
\hline $2000 \mathrm{~s}$ & 16,879 & 0.660 & 0.051 & 0.457 & $2000 \mathrm{~s}$ & 31,304 & 0.543 & 0.031 & 0.429 \\
\hline Avg. & 14,351 & 0.417 & 0.053 & 0.572 & Avg. & 14,881 & 0.200 & 0.020 & 0.520 \\
\hline
\end{tabular}

LAPG: League annual average attendance per game.

GU: We compared three measures but "tail likelihood" $\left(\mathrm{TL}_{t}\right)$ became the main focus (it is the only GU variable covered in this table). $\mathrm{TL}_{t}$ is the excess of observed tail frequencies of high or low winning percentages over "idealized" frequencies that would occur if all teams were of equal playing strength (supposing the probability that any team will defeat any other equals 0.5 ). If $\mathrm{TL}_{t}$ increases, the tails of the distribution are moving closer to the league average winning percentage, that is, outcome uncertainty increases. We also examined the ratio of standard deviations. Let $\mathrm{ASD}_{t}$ be the actual standard deviation of winning percentages for a league in a given year. Let $\mathrm{ISD}_{t}$ be the standard deviation of an "idealized" league where the probability that any team beats any other team is 0.5 , namely for the binomial, $\frac{0.5}{\sqrt{m}}$, where $m$ is season length. The ratio of standard deviations is $\mathrm{RSD}_{t}=\frac{\mathrm{ASD}_{t}}{\mathrm{ISD}_{t}}$. As $\mathrm{RSD}_{t}$ increases, outcome uncertainty declines. We also examined $\mathrm{HICB}_{t}=\frac{4}{N_{t}} \sum_{i=1}^{N_{t}}\left(\frac{w_{i}}{r}\right)_{t}^{2}$, where $N_{t}$ is the number of teams in the league in year $t, w_{i}$ is wins by team $i$, and $r$ is the total number of games in the season in year $t$. Outcome uncertainty declines with higher values of $\mathrm{HICB}_{t}$.

PU: We use a variant of the measure cited in the text since we can only evaluate at season's end for our annual league-level aggregate of attendance. The measure is given by, $\mathrm{PLU}_{t}=\frac{1}{N} \sum_{i=1}^{N} f\left(\mathrm{~GB}_{i, t} \frac{\max (G)}{G_{t}}\right) . N$ is the number of teams other than division winners in a league, $f$ is $n \sim(0,6)$, and $\max (G)$ is the maximum number of games played over the sample period for the league. For $\mathrm{GB}_{i}$, let $\mathrm{GB}_{i d}$ be the number of games back for a team that is $i$ wins behind the division winner and let $\mathrm{GB}_{i w}$ be the number of games back for a team that is $i$ wins behind the wild-card winner. $\mathrm{GB}_{i}=\min \left(\mathrm{GB}_{i d}, \mathrm{~GB}_{i w}\right)$. As $\mathrm{PLU}_{t}$ increases, outcome uncertainty declines.

CSU: $\mathrm{CORR}_{t}$ is the correlation across teams between $\mathrm{WP}_{i, t}$, winning percentage for team $i$, year $t$, and $\frac{1}{3} \sum_{s=t-3}^{t-1} \mathrm{WP}_{i, s}$. Outcome uncertainty declines as $\mathrm{CORR}_{t}$ increases.

measure that only uses one prior season. It is more reasonable to think of CSU across more than one season of reference. ${ }^{10}$

We found that there is the high correlation in all leagues within the three GU measures

10. For our aim-specifying separately GU, PU, and CSU-we passed on Humphreys' (2002) competitive balance ratio and Lenten's (2009) top team concentration index because each is a hybrid of types of balance and has the chance to confuse GU and PU. We also could not determine how to calculate Owen's (2010) higher moments (range and listed above, except in the NHL. The correlations between RSD and HICB are between .856 and .980 . However, there are only a few signs of mild to strong correlation between these GU measures and PLU (our chosen measure of PU) and CORR (our chosen measure of CSU).

variance) of the ratio of standard deviations measure for the unbalanced schedules and larger leagues/divisions of up to 15 teams in our data. 


\section{Data Issues and Adjusted Series}

There are a number of issues with raw attendance data. ${ }^{11}$ Each league has had either a strike (players refuse to work) or lockout (owners refuse to run part or all of a season) at some point. While previous literature has made use of indicator variables to denote strike and lockout years (Schmidt and Berri 2002, 2004; Coates and Harrison 2005), this can adversely affect detection of long-term structural change elsewhere in the data where the series may be partitioned into short subsamples by the indicator variables. Therefore, in addition to the raw LAPG, we make use of an adjusted version to handle labor disputes that actually resulted in lost games for fans. For those years, the adjustment takes a weighted average LAPG of the seasons just before games were lost, during the season where games were lost, and just following the year where games were lost, as in Lee and Fort (2008). In the case of the 2004-2005 NHL season lost in its entirety, we average data from one season before and after the work stoppage. This adjustment ensures that later breakpoint size and location estimation is not falsely influenced by the short-term shocks that may result from a work stoppage, as the works just cited find short-term effects of strikes, rather than long-term. Lastly, we assume the average of reported games was the same over all games for a few NFL teams that did not report the attendance at all of their games for 2008 and 2009. ${ }^{12}$

\section{Methodology}

We follow the approach outlined in Fort and Lee (2006) as actually implemented by Lee and Fort (2008). The first step is to test each attendance series against the null of a unit root. Then, if needed, stationarity with break points is assessed. Third, using what is now referred to as the "BP method" (Bai and Perron 1998, 2003, 2006), the statistical significance

11. For example, while LAPG for early NHL games was nearing 15,000 , league expansion reportedly decreased LAPG by 3,500. While the Oakland Seals saw LAPG in this range (Kurtzberg 2009), it seems unlikely that Los Angeles, Minnesota, Philadelphia, Pittsburgh, and St. Louis did. After this short initial period of low reported attendance, reports rebounded (just before the formation of the WHA in 1972). We return to this issue later.

12. The 2008 San Francisco 49ers and 2009 Tampa Bay Buccaneers reported attendance for only seven games, as they played one of their home games in London, United Kingdom, leaving this number out of their reports. and qualitative characteristics of the break point is determined. Finally, the impact of our $\mathrm{UOH}$ measures on attendance is estimated, taking into account break points in the data.

The unit-root hypothesis was tested using the Augmented Dickey-Fuller (ADF) and PhillipsPerron (PP) tests with both a constant and with a trend. The numbers of lags were determined by minimization of the Schwartz-Bayesian criterion for the ADF test, and by the truncation suggested by Newey and West (1994) for the PP test. Unit-root tests were further verified using the generalized least squares Dickey-Fuller test (DFGLS) as described in Elliot, Rothenberg, and Stock (1996).

Leybourne, Mills, and Newbold (1998) highlight the possibility of spurious rejections of unit-root presence with Dickey-Fuller tests when breaks are near the beginning of a nonstationary series. We therefore employ the twobreak minimum LM unit-root test irrespective of the results from the ADF and PP tests (Lee and Strazicich 2001, 2003, 2004; Perron 1989). Following results from this procedure, we employ a one-break minimum LM unit-root test (Lee and Strazicich 2001) for series that are not rejected at the highest level with the two-break test. Lastly, we further verify the unit root with break results using the Zivot-Andrews test (Zivot and Andrews 1992). ${ }^{13}$

For each league attendance series in which a unit root is rejected, or rejected with break points, we apply the approach of Bai and Perron $(1998,2003,2006)$ to ascertain the statistical significance and qualitative behavior of the breaks allowing changes in both levels and trends as first described in Perron (1989). Our model for each league parallels that used on MLB in Lee and Fort (2008) and we do not reprise it here. Suffice to say that we perform the BP method on each league as a separate regression, including the impacts of our UOH variables where only coefficients on the time trend and level are allowed to change across regimes, while the coefficients pertaining to $\mathrm{UOH}$ variables are not. This is classified as the partial model in Bai and Perron (2003).

We present model results that assume homogeneous error estimates across regimes for the statistical tests with the suggested trimming

13. For brevity, we do not report the results of the DFGLS or Zivot-Andrews test here; however, the results of these are available upon request. 
TABLE 2

Results of Unit-Root Tests

\begin{tabular}{|c|c|c|c|c|}
\hline $\begin{array}{l}\text { League } \\
T \text { (seasons) }\end{array}$ & & $\begin{array}{c}\text { NBA } \\
55\end{array}$ & $\begin{array}{c}\text { NFL } \\
76\end{array}$ & $\begin{array}{c}\text { NHL } \\
50\end{array}$ \\
\hline $\operatorname{ADF}(p)$ & Constant & $-0.883(1)$ & $-2.017(1)$ & $-1.210(1)$ \\
\hline $\operatorname{ADF}(p)$ & Trend & $-1.287(1)$ & $-2.233(1)$ & $-2.682(1)$ \\
\hline $\mathrm{PP}(l)$ & Constant & $-0.965(3)$ & $-1.774(3)$ & $-1.399(3)$ \\
\hline $\mathrm{PP}(l)$ & Trend & $-1.406(3)$ & $-1.905(3)$ & $-2.987(3)$ \\
\hline \multicolumn{5}{|l|}{ 2-Break LM } \\
\hline & $\hat{k}$ & 7 & 3 & 6 \\
\hline & $\hat{T}_{b 1}$ & $1972 / 1973$ & 1972 & $1973 / 1974$ \\
\hline & $\hat{T}_{b 2}$ & 1996/1997 & 2000 & $1985 / 1986$ \\
\hline & Test Stat. & $-5.714 * *$ & $-6.076^{* *}$ & $-6.323 * *$ \\
\hline \multicolumn{5}{|l|}{ 1-Break LM } \\
\hline & $\hat{k}$ & 7 & 8 & 3 \\
\hline & $\bar{T}_{b}$ & 1992/1993 & 1980 & $1976 / 1977$ \\
\hline & Test Stat. & $-5.182 * * *$ & -3.431 & $-4.580 * *$ \\
\hline
\end{tabular}

$p$, the number of lags; $l$, lag truncation; $\hat{k}$ is the optimal number of lagged first-difference terms included in the unit-root test to correct for serial correlation. $\hat{T}_{b}$ denotes the estimated break points. See Table 2 of Lee and Strazicich (2003) for critical values. $* * *, * *, *=$ significant at $99 \%, 95 \%$, and $90 \%$ critical levels, respectively. See Lee and Fort (2008) for unit roots of MLB American and National Leagues.

parameter $(\varepsilon=0.15) .{ }^{14}$ While we also examined results assuming heterogeneous error estimates across regimes with a larger trimming parameter, the only differences produced by the two models occurred in the NHL and we detail later why we believe the homogeneous version is more useful. We use current year measures of balance, rather than lagged versions since it seems reasonable that outcome uncertainty in the current year would be more desirable to fans than the previous year. Finally, we report the results of the BP method on the attendance data adjusted for labor issues (results for unadjusted data are available upon request).

\section{RESULTS OF ANALYSIS}

As detailed in all of the above, the results of our analysis should inform us on four main points - stationarity characteristics of the data (roughly identifying breaks in the attendance time series), sorting out the issue of the measurement of GU over the entire distribution of winning or just in the tails, the determination of the significance of the break points (we add a brief look at the economic as well as statistical significance) in the attendance time series for each league. Finally, and the punch line, is the

14. Bai and Perron (2006) discuss the size and power properties of the structural break tests under certain conditions. impact of the $\mathrm{UOH}$ on attendance through $\mathrm{GU}$, PU, and CSU.

\section{A. Stationarity}

Unit-root test results are in Table 2. For all three leagues, we fail to reject the presence of a unit root in the data using the Augmented Dickey-Fuller and Phillips-Perron tests. We follow with Lagrange Multiplier tests for stationarity with break points from Lee and Strazicich (2001, 2004). The two-break test rejects the presence of a unit root at the $95 \%$ critical level for all three leagues.

If the attendance series are stationary with only a single break, the power of the two-break test may be reduced. Therefore, we also apply the one-break test for all leagues, as none of the attendance series were rejected at the highest critical level (99\%). The one-break test rejects the presence of a unit root with breaks at the 99\% critical level for the NBA but not for the NFL. We proceed under the assumption that all attendance series are stationary with one or two breaks.

\section{B. Sorting Out $G U$}

In order to investigate how GU might enter into the determination of attendance, we investigated break points using each of RSD, HICB, and TL in combination with PLU and CORR (results available upon request). We compared 
TABLE 3

Bai and Perron Model 1 Break Test Results

\begin{tabular}{|c|c|c|c|c|c|}
\hline League & $T_{1}$ & $T_{2}$ & $T_{3}$ & $T_{4}$ & $T_{5}$ \\
\hline NBA & $\begin{array}{c}\mathbf{1 9 8 7}-\mathbf{1 9 8 8} \\
{[1986-1987,1988-1989]}\end{array}$ & $\begin{array}{c}\mathbf{1 9 9 7 - 1 9 9 8} \\
{[1996-1997,2000-2001]}\end{array}$ & & & \\
\hline NFL & $\begin{array}{c}1973 \\
{[1972,1974]}\end{array}$ & $\begin{array}{c}1997 \\
{[1996,2000]}\end{array}$ & & & \\
\hline NHL & $\begin{array}{c}\mathbf{1 9 6 6 - 1 9 6 7} \\
{[1965-1966,1967-1968]}\end{array}$ & $\begin{array}{c}\mathbf{1 9 7 5}-\mathbf{1 9 7 6} \\
{[1974-1975,1976-1977]}\end{array}$ & $\begin{array}{c}\mathbf{1 9 9 4 - 1 9 9 5} \\
{[1993-1994,1995-1996]}\end{array}$ & & \\
\hline $\mathbf{A L}$ & $\begin{array}{c}\mathbf{1 9 1 8} \\
{[1917,1919]}\end{array}$ & $\begin{array}{c}1945 \\
{[1944,1946]}\end{array}$ & $\begin{array}{c}\mathbf{1 9 6 3} \\
{[1962,1964]}\end{array}$ & $\begin{array}{c}1978 \\
{[1977,1981]}\end{array}$ & $\begin{array}{c}1994 \\
{[1993,1996]}\end{array}$ \\
\hline NL & $\begin{array}{c}1918 \\
{[1917,1919]}\end{array}$ & $\begin{array}{c}1945 \\
{[1944,1946]}\end{array}$ & $\begin{array}{c}\mathbf{1 9 7 6} \\
{[1975,1979]}\end{array}$ & & \\
\hline
\end{tabular}

Notes: $90 \%$ confidence intervals are in []. Lee and Fort (2008) break points were as follows:

AL: 1918, 1945, 1962, 1987; NL: 1918, 1945, 1967.

the $\mathrm{UOH}$ results for each combination and the outcome was completely consistent for the NHL, $\mathrm{AL}$, and $\mathrm{NL}$ - the $\mathrm{UOH}$ for all three types of outcome uncertainty was rejected regardless of which GU measure was used. However, for the NBA and NFL, the UOH results depended on whether TL or HICB was used to measure GU (but not RSD, so it was dropped from further consideration).

We chose TL for the NFL since the adjusted $R^{2}$ value was about the same as for HICB but HICB identified one more break than did TL. ${ }^{15}$ To us, this suggests that the TL measure captured something that HICB simply left unexplained in the added break point. Further, since $\mathrm{UOH}$ results were the same in the NHL, AL, and NL for any of the GU measures, we also use TL for hockey and baseball. However, none of these criteria distinguished TL from HICB for the NBA; both gave the same break points (by overlapping confidence intervals) and about the same adjusted $R^{2}$. For the sake of comparison, we report results consistently across all leagues using TL but point out the differences that occur when HICB is used instead for the NBA.

\section{The BP Method and Break Points in Attendance}

The BP test results are in Table 3. Since we employ a different measure for PU than Fort

15. The caution we followed is that one cannot choose just on goodness of fit unless the same break points are identified by covariates under comparison because of how our chosen breakpoint method works-breakpoint determination goes along with the choice of variables so adjusted $R^{2}$ might go up just because another break point is identified, not because the covariates got any stronger. and Lee (2008), we also include the results of our model for the AL and NL. The break points we find for the AL and NL are quite different beyond the earliest in 1918 and 1945 in both leagues and then 1962 in the AL. We note that very little information can be gleaned from the upcoming discussion of coefficient estimates for level shifts in the model. For this reason, we plot the fitted value of adjusted attendance for all leagues in Figures 1 and 2. We offer the example of the results for the NBA and leave the results for the other leagues to the reader (more substantive coverage is in the following section on situational similarities). Figure 1 shows that the 1987-1988 break point for the NBA dramatically shifted attendance upward. An upward trend followed at about the same rate as the upward trend that characterized NBA attendance prior to the first break. The 1997-1998 break point shows only the slightest decline in attendance followed by a barely perceptible upward trend.

\section{Attendance and Outcome Uncertainty: Statistical and Economic Significance}

Table 4 shows the attendance estimation results. Table 5 summarizes the implications of our estimation for the $\mathrm{UOH}$ for all leagues. We also include the results for MLB from Lee and Fort (2008) on MLB. We note immediately that we do not find the same support for the UOH regarding PU that they found earlier. Partly, their analysis was on a shorter sample but the primary difference is that the measure of PU we use, PLU, incorporates the entire distribution of play-off contending teams rather than just those in first and second place. 
FIGURE 1

Plot of Fitted NBA, NFL, and NHL LAPG
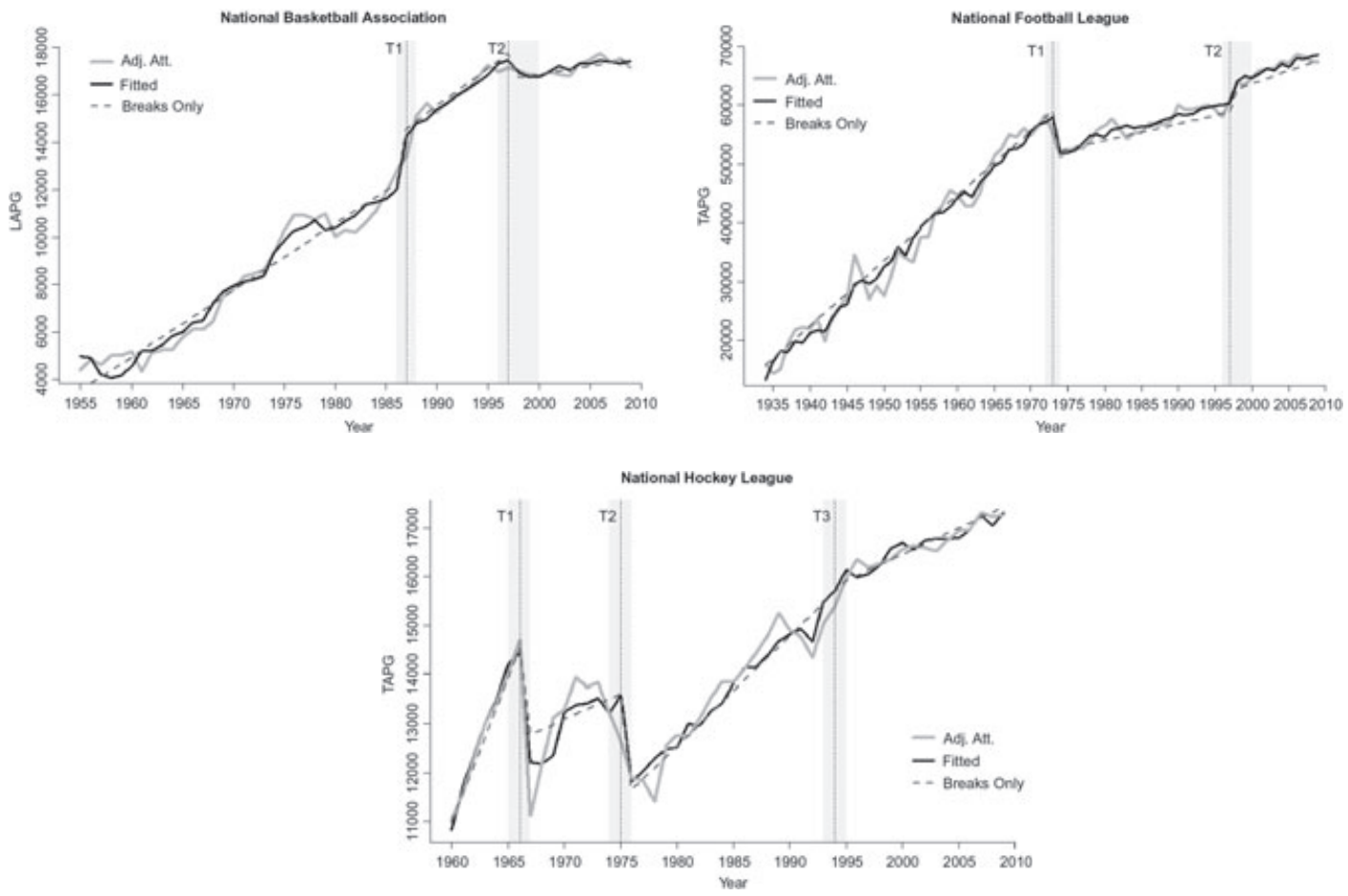

FIGURE 2

Plot of Fitted AL and NL (MLB) LAPG

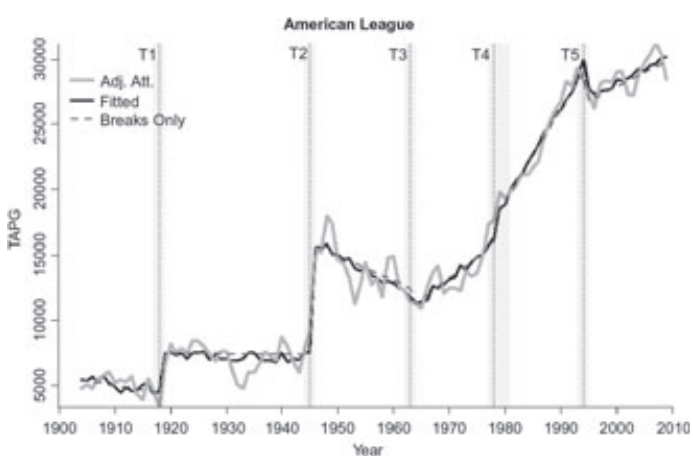

The first striking result to us in Table 5 is that there is extremely limited evidence supporting Rottenberg's UOH. GU for the NBA impacts attendance in accord with the UOH. As TL rises, and GU improves, attendance increases. If the NBA owners care about balance because fans do, then they are better off facilitating closely

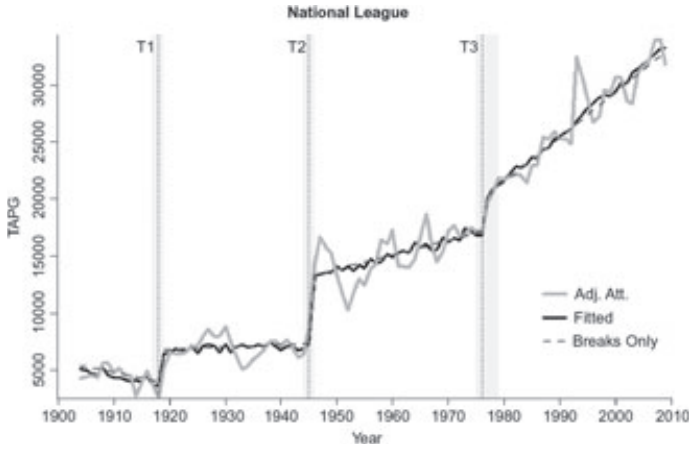

contested individual games. But we hasten to add that if one uses HICB rather than TL for the NBA, it would be CSU rather than GU that would have a statistically significant impact and fail to reject the UOH (break points remain the same plus or minus their confidence intervals). This suggests to us that further empirical work 
TABLE 4

Breakpoint Regression Results

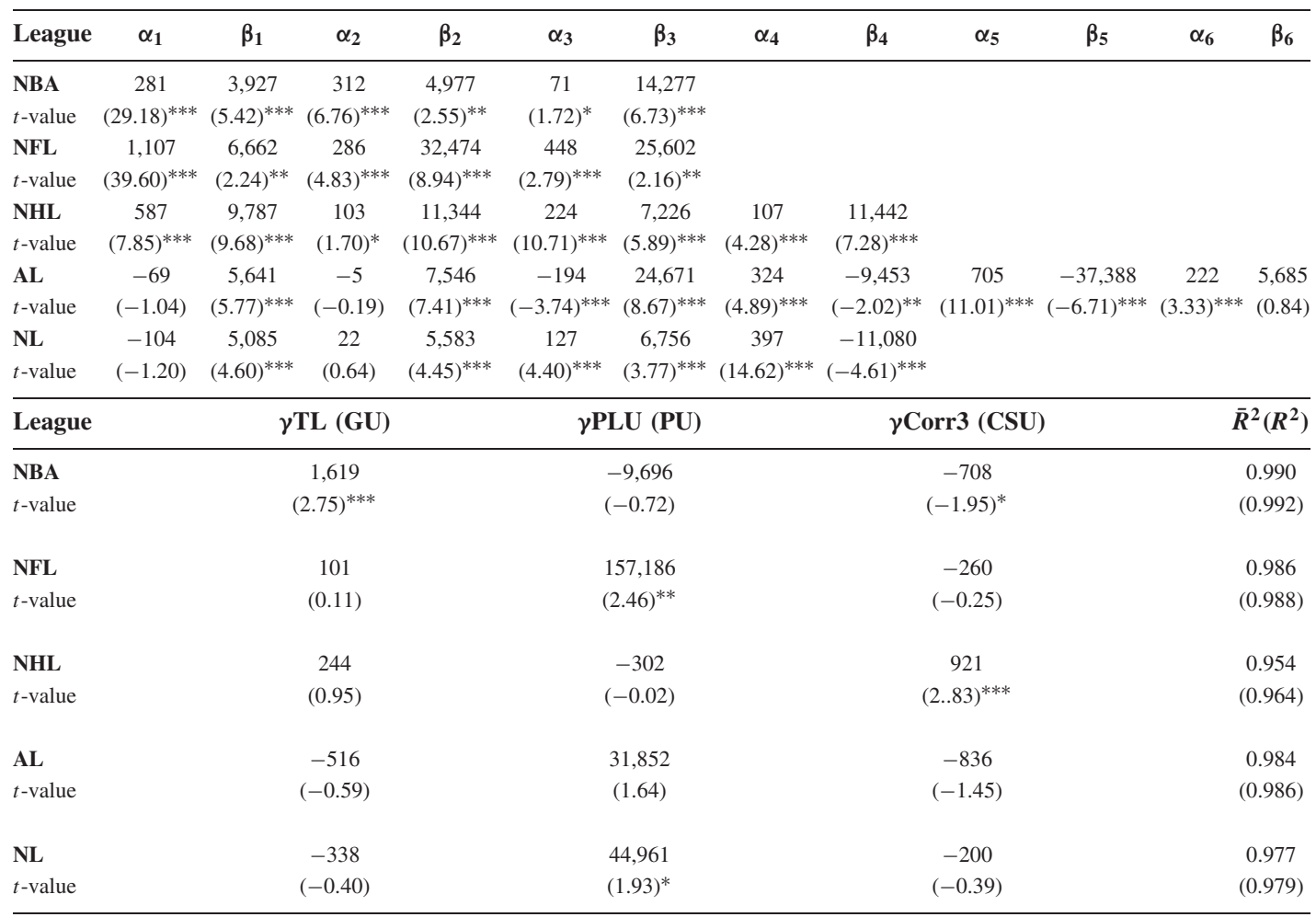

\footnotetext{
*** Significant at the $99 \%$ critical level.

** Significant at the $95 \%$ critical level.

* Significant at the $90 \%$ critical level.

$\alpha_{M}$ and $\beta_{M}$ refer to the slope and intercept coefficients for regime $M$, respectively.
}

TABLE 5

UOH Summary

\begin{tabular}{lccc}
\hline League & GU & PU & CSU \\
\hline NBA & Fail to reject $^{\mathrm{a}}$ & Reject $^{\mathrm{b}}$ & Reject \\
NFL & Reject & Fail to reject & Reject \\
NHL & Reject & Reject & Reject $(-)^{\text {c }}$ \\
MLB $^{\text {d }}$ & Reject & Reject & Reject \\
\hline
\end{tabular}

a"Fail to reject": Estimated coefficient yields statistically significantly positive relationship between the given measure of outcome uncertainty and attendance.

b"Reject": Estimated coefficient yields statistically insignificant relationship between the given measure of outcome uncertainty and attendance.

c"Reject (-)": Estimated coefficient yields statistically significantly negative relationship between the given measure of outcome uncertainty and attendance.

${ }^{\mathrm{d}}$ Lee and Fort (2008) found the following: $\mathrm{GU}=$ Reject, $\mathrm{PU}=$ Fail to reject, $\mathrm{CSU}=$ Reject.

on the actual preferences of NBA fans toward $\mathrm{GU}$ is in order-in other types of fan preference models, are they more in tune with the tails or the overall distribution of winning percentages? The only other piece of evidence supporting Rottenberg's UOH is for PU in the NFL. If NFL owners care about balance because fans do, they should facilitate tight division championship races.

Now, as we have repeatedly stated, Rottenberg never directly addressed the question of CSU; that is, dynasties. The results in Table 5 show overwhelmingly that any version of the $\mathrm{UOH}$ extended to dynasties is simply rejected (unless NBA fans adhere to HICB rather than PL for GU, in which case the evidence supports the UOH for CSU in the NBA). In addition, judging by the significantly negative response of attendance to an improvement in CSU, NHL fans appear to like dynasties. However, we caution that the result for the NHL may be due to the inability of the BP method to handle two closely adjacent break points. In 1967-1968, the NHL doubled in size from 6 to 12 teams. 
This expansion had an effect on the competitive balance of the league, especially for CSU measured by CORR. The CORR measure during the first 3 years of expansion includes six NHL teams in its calculation, as the expansion teams do not have 3 years' worth of win data to include in the measure. This calculation issue made the CSU variable drop considerably for these 3 years only, returning to previous levels once all teams have available data to include in the calculation. Given that the first NHL break is not as large as the entire attendance dip during this short period, the approach may be attributing much of the decrease in attendance to the improvement in CSU.

This lack of any support at all for the $\mathrm{UOH}$ in the NHL and the two MLB leagues makes them much like the European leagues as assessed by Szymanski (2003). However, at least at the annual league level, there appears to be variation in the importance of outcome uncertainty and the type of outcome uncertainty that matters for attendance in the NBA and the NFL. This suggests that there are truly interesting and insightful differences to be discovered among fans of the major North American sports leagues in future work on data at a less aggregate level. However, we repeat the caution that researchers using those data mind the break points determined in the last section.

Statistical significance does not guarantee economic significance. Therefore, we take the Lee and Fort (2008) approach that incrementally changes balance measures to produce attendance increases to estimate the effects this would have on stadium revenues. The data are from Team Marketing Report for 2009 found at Rod's Sports Business Data (2012a, 2012b, 2012c). For example, for GU, statistically significant for the NBA, we improve GU by the average change in the TL measure from year to year. We do similarly for an improvement in PU for the NFL and a worsening in CSU for the NHL. We then determine the change in attendance that results and apply the correctly normalized dollar values from the Team Marketing Report, Fan Cost Index data for 2009. The results are in Table 5.

If the NBA were able to take actions in our chosen incremental fashion, the league would enjoy a $0.60 \%$ increase in revenues for improved GU. While statistically significant, this result indicates that the economic significance of outcome uncertainty to the NBA is minimal, about $\$ 7,300$ per game or about $\$ 300,000$ for 41 home
TABLE 6

Economic Significance of Outcome Uncertainty (Statistically Significant Coefficients Only)

\begin{tabular}{|c|c|c|c|}
\hline & NBA & NFL & NHL \\
\hline Value calculation & GU & PU & CSU \\
\hline 2009 LAPG & 17,132 & 67,426 & 17,476 \\
\hline 2009 Variable & 0.030 & 0.058 & 0.378 \\
\hline Coef. est. $^{\mathrm{a}}$ & 1,619 & 157,186 & 921 \\
\hline Elasticity & 0.0028 & 0.1352 & 0.0199 \\
\hline$\Delta$ Variable $^{\mathrm{b}}$ & 0.064 & 0.004 & 0.184 \\
\hline Inc. Factor & $213.3 \%$ & $6.9 \%$ & $48.7 \%$ \\
\hline$\triangle \mathrm{LAPG}$ & 102.3 & 629.0 & 169.4 \\
\hline$\% \triangle \mathrm{LAPG}$ & $0.60 \%$ & $0.93 \%$ & $0.97 \%$ \\
\hline Rev. Per Attend ${ }^{\mathrm{c}}$ & $\$ 71.93$ & $\$ 103.16$ & $\$ 75.14$ \\
\hline$\Delta$ Game Rev. & $\$ 7,358$ & $\$ 64,887$ & $\$ 12,729$ \\
\hline
\end{tabular}

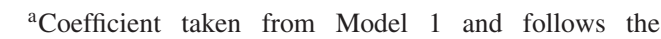
approach of Lee and Fort $(2008,291)$.

${ }^{\mathrm{b}}$ All measures interpreted by definition, not coefficient sign in the model.

${ }^{c}$ Revenue per attendee data come from Team Marketing Report, Fan Cost Index data, 2009.

games for a team. ${ }^{16}$ This would seem to require extreme micro-level management for a less than $1 \%$ increase in total league revenues.

Using a similar approach to PU in the NFL, the revenues gained are again minimal for the league, an increase of only $0.93 \%$. This amounts to about $\$ 65,000$ in game revenues, or about $\$ 520,000$ for eight home games in the regular season for each team. This total for the entire league equates to the salary of one 3-year veteran player contracted at the league minimum.

Exactly the same approach and logic also reveals that the statistical significance of CSU for the NHL ends up truly trivial, economically. If the NHL were able to take action that reduced CSU in the incremental fashion we devise, the result would be about a $0.97 \%$ increase in league revenues translating into approximately $\$ 520,000$ per team for 41 home games.

\section{SITUATIONAL SIMILARITIES AND FURTHER RESEARCH}

A few situational similarities across leagues suggest interesting general topics for further research. The first concerns truly macro events. The earliest break points are only found for baseball and have been attributed elsewhere to

16. We note that the year-to-year change in $\mathrm{GU}$ is rather large, highlighting the particularly economically trivial impact of micromanaging GU in the NBA. 
the two world wars (Fort and Lee, forthcoming). The NFL (founded 1920) came after World War I and was fully functioning at World War II. One interesting area for future research might be why World War II impacted baseball but not hockey or football (at least as far as attendance shifts go). ${ }^{17}$

The next situational similarity is league expansion. The break points in the 1960s coincided with expansion in both the AL in baseball and the NHL; the shifts were both downward. The only break point in the 1980s coincided with expansion in the NBA and the shift was in the opposite direction. It is easy to see why there was this difference between baseball and hockey, on the one hand, and basketball on the other. AL expansion followed the move of the Washington Senators to Minnesota (Twins); expansion teams were placed in Washington, DC (Senators II) and Los Angeles (Angels). Neither the moves nor the expansion involved especially talented teams and none drew very well. The NHL added Philadelphia, Los Angeles, St. Louis, Minnesota, Pittsburgh, and Oakland to become a 12-team league in 1967-1968. The downward shift could easily be a combination of the complete segregation of all expansion teams into the West Division with all original eight teams into the East Division, and poor attendance in these new markets (especially true of Oakland). ${ }^{18}$ In the NBA, it is reasonable that attendance would shift upward instead. The Charlotte Hornets and Miami Heat joined for the 1988-1989 season and the Orlando Magic and Minnesota Timberwolves joined the very next season, 1989-1990. The Florida markets were large and attendance was high. ${ }^{19}$ Additionally,

17. The question does not extend to the NBA (founded 1946-1947) since it was founded during World War II and we do not know whether the NHL (founded 1917-1918) would be included in the question because our data do not go that far back.

18. The subsequent upward trend in hockey attendance coincides with further expansion to Buffalo and Vancouver for the 1970-1971 season. The two outdrew some of the most prominent teams in the league like the Detroit Red Wings and Boston Bruins after only 2 years in the league.

19. There are two complicating factors for the NBA. The first is related to the move of some teams to new arenas. Second, Magic Johnson and his L.A. Lakers teammate Kareem Abdul Jabbar would retire shortly after the 1987-1988 break point and the Celtics' Larry Bird just after them, ending a long-running charismatic NBA episode. While entering the league for the 1984-1985 season, the Bulls' Jordan matured as the previous era ended. As rosters are so much smaller than in any other sport, charismatic (as well as proficient) stars may have larger individual impacts than in any other sport.
Detroit, Milwaukee, and Sacramento moved to new arenas, nearly doubling the seating capacity for these teams. Of course, this begs the research question on just why leagues took such different expansion approaches and why other expansions do not coincide with any break points at all (e.g., the NL for the 1993 season).

A third situational similarity coinciding with the break points in the 1970s is league merger. The NFL merger (1970) occurred just prior to an attempted rival league, the WFL (1974-1975). The NHL, on the other hand, faced a truly viable rival league, the WHA (1972-1973 to 1978-1979). The Edmonton Oilers, New England Whalers, Quebec Nordiques, and Winnipeg Jets merged into the NHL and that was that for the WHA. The similarity here suggests fruitful research on the choices made by owners through their leagues in the face of potential and actual rival leagues.

The final situational similarity is strikes and lockouts that actually denied fans portions of regular season games and in some cases playoffs and championships. The break points in the 1990s coincide with the 1994-1995 MLB strike (lost portion of the 1994 regular season, play-offs and World Series, and a portion of the 1995 season) for the $\mathrm{AL},{ }^{20}$ the 1994-1995 lockout in the NHL (reduced the regular season from 82 to 48 games), ${ }^{21}$ and the 1998-1999 NBA lockout (reduced the regular season from 82 to 50 games). For baseball, attendance shifts down and the trends are flatter than before the shift. This seems entirely consistent with fans that are put off by the strike and dampen their attendance after it ends. Despite adjusting our LAPG for just such an occurrence, there are perhaps more lasting impressions from a strike in MLB than could be found in previous work on the subject (Schmidt and Berri 2002, 2004; Coates and Harrison 2005). For the rest, the timing of the break points suggests a complex

20. One explanation for the lack of a similar break point in the NL is that NL expansion occurred with Florida (the Marlins) and Colorado (the Rockies) beginning play in 1993. The Rockies topped the attendance chart in both leagues while the Marlins were a respectable 5th in the NL.

21. Due to the constraints on estimating breaks near endpoints, the BP method is unable to detect anything about the NHL lockout in 2004-2005. Visual inspection does not raise any concern about changes due to the lockout, and it could be that rule changes adopted after the lockout, added enough excitement to the game as to counteract any backlash that may have occurred. We suspect, instead, that it is worth returning to the question after a few years more of data are generated. 
substitution process that may have been missed in previous work and goes as follows.

First, there is a rather large upward movement in attendance that coincides with the NHL break possibly indicating fans from MLB (specifically the AL based on the break dates) began attending NHL games due to the absence of baseball. Second, the lower end of the confidence interval on the NBA break point (1996-1997) suggests that NBA attendance demand may have reached its peak or that reported attendance was at or near capacity just following the labor issues that plagued both the NHL and MLB in 1994 and 1995. Perhaps the upward movement in NBA attendance followed fan substitution from these two sports to the NBA and abruptly ended as these leagues returned to play. Finally, while there was no strike or lockout in the NFL at its break point (well after the 1993-1994 strike), ${ }^{22}$ the league may well have enjoyed an attendance bump coincident with the decline that occurred in the NBA. Previous work has found little evidence of hockey-to-basketball substitution (Winfree and Fort 2008) but perhaps the substitution patterns are more complex than captured there.

\section{CONCLUSIONS AND REMAINING IMPLICATIONS FOR FUTURE RESEARCH}

We use the BP method to assess the time series behavior of annual league attendance per game for the North American major leagues. The series are all nonstationary but stationary with break points. This result should be of interest to statistical analysts using level data. If they wish to avoid spurious correlation outcomes, they should exercise caution and use the stationary subsets of the attendance data we identify.

We also estimate the effects of game uncertainty and play-off uncertainty, addressed directly by Rottenberg's UOH, on aggregate league attendance. Supporting evidence includes only game uncertainty for the NBA and play-off uncertainty for the NFL. Our findings of no support for the UOH in MLB is at odds with the previous findings, using a different PU measure, by

22. There were other things going on in the NFL as well (the Oilers' move from Houston to Tennessee, rule changes, the entry of FOX into the broadcast market, and improved on-screen TV viewing innovations). However, the league had an earlier occurrence of a 42-day training camp strike in 1974 that may have soured the fans for that season, with some evidence for fan substitution between football and baseball.
Lee and Fort (2008). In addition, we estimate the effect of consecutive season uncertainty, which Rottenberg did not address, on gate attendance in each of these leagues. Increased consecutive season uncertainty decreased attendance in the NHL. The result might be due to a shortcoming in our technique, as closely adjacent break points would require reducing the trimming parameter below that suggested by Bai and Perron (2006). We hasten to point out that some results depend on which measure of GU is used and that future work should pay explicit attention to the investigation of such measures. Almost certainly these results will prove interesting in all further crosssection/time series assessments of the role of fan preferences in attendance demand. It would also be interesting to see how these results relate to television demand, and the natural extension of GU research calls for further examination of attendance at the game level.

It is important to note that we do not consider sellouts for league-aggregate attendance, and this could affect our findings with respect to the effects of balance measures especially for the NFL where sellouts are the most common. More work is needed to evaluate the effects of uncertainty on NFL attendance because of this issue. Unfortunately, our breakpoint method only allows for ordinary least squares regression at this point in time. Further inspection at the franchise level for some teams-especially in the NFL_-would certainly require further consideration of sellouts in a limited dependent variables framework.

Finally, despite the statistical significance of some of our estimated outcome uncertainty coefficients, the economic significance of outcome uncertainty tends to be minimal. Marginal alterations in outcome uncertainty can improve league revenues only trivially in the NBA, NFL, and NHL. It may be that the leagues in this analysis have managed balance well enough that it does not negatively affect fan interest in the league.

Given that balance seldom matters at this aggregate level, and when it does it does not matter much, leads to our final research suggestions. There is now ample evidence that outcome uncertainty really just does not matter (much) for North American pro sports in the way Rottenberg suggested. However, Rottenberg's is the typical logic espoused by team owners, acting through their league, as justification for policy impositions like the draft, revenue sharing, and salary caps. If not for the 
sake of balance, then why are the policies actually supported? Economists are well equipped to examine the distributional consequences of these policies between players and owners, and some owners and others.

\section{REFERENCES}

Andrew's Dallas Stars Page. "NHL Average Attendance Since 1989-90." 2010. Accessed March 21, 2010. http://www.andrewsstarspage.com/index.php/site/ comments/nhl_average_attendance_since_1989_90/ 118-2008-09.

Baade, R. A., and L. J. Tiehen. "An Analysis of Major League Baseball Attendance 1969-1987.” Journal of Sport and Social Issues, 14, 1990, 14-32.

Bai, J., and P. Perron. "Estimating and Testing Linear Models with Multiple Structural Changes." Econometrica, 66, 1998, 47-78.

. "Computation and Analysis of Multiple Structural Change Models." Journal of Applied Econometrics, 18, 2003, 1-22.

. "Multiple Structural Change Models: A Simulation Analysis," in Econometric Theory and Practice: Frontiers of Analysis and Applied Research, edited by D. Corbae, S. N. Durlaff, and B. E. Hansen. New York: Cambridge University Press, 2006, 212-37.

Basketball-Reference. "NBA Season Summary." 2012. Accessed November 6, 2012. http://www.basketballreference.com/leagues/NBA_2010.html.

Borland, J., and R. Macdonald. "Demand for Sport." Oxford Review of Economic Policy, 19, 2003, 478-502.

Bruggink, T. H., and J. W. Eaton. "Rebuilding Attendance in Major League Baseball: The Demand for Individual Games," in Baseball Economics: Current Research, edited by J. L. Fizel, E. Gustafson, and L. Hadley. Westport, CT: Praeger, 1996.

Butler, M. R. "Competitive Balance in Major League Baseball." American Economist, 39, 1995, 46-52.

. "Interleague Play and Baseball Attendance." Journal of Sports Economics, 3, 2002, 320-34.

Coates, D., and T. Harrison. "Baseball Strikes and the Demand for Attendance." Journal of Sports Economics, 6, 2005, 282-302.

Coates, D., and B. Humphreys. "Ticket Prices, Concessions and Attendance at Professional Sporting Events." International Journal of Sport Finance, 2, 2007, $161-70$.

Coffin, D. A. "If You Build It Will They Come?," in Baseball Economics: Current Research, edited by J. L. Fizel, E. Gustafson, and L. Hadley. Westport, CT: Praeger, 1996.

Davies, B., P. Downward, and I. Jackson. "The Demand for Rugby League: Evidence from Causality Tests." Applied Economics, 27, 1995, 1003-07.

Davis, M. C. "The Interaction Between Baseball Attendance and Winning Percentage: A VAR Analysis." International Journal of Sport Finance, 3, 2008, 58-73.

Demmert, H. G. The Economics of Professional Team Sports. Lexington, MA: D.C. Health, 1973.

Dobson, S., and J. Goddard. The Economics of Football. Cambridge, UK: Cambridge University Press, 2001.

Domazlicky, B. R., and P. M. Kerr. "Baseball Attendance and the Designated Hitter." American Economist, 34, 1990, 62-68.

Elliott, G., T. J. Rothenberg, and J. H. Stock. "Efficient Tests for an Autoregressive Unit Root." Econometrica, 64, 1996, 813-36.
Fort, R. "Comments on "Measuring Parity." Journal of Sports Economics, 8, 2007, 642-51.

Fort, R., and Y. H. Lee. "Stationarity and MLB Attendance Analysis." Journal of Sports Economics, 7, 2006, $408-15$.

- Forthcoming. "Major League Baseball Attendance Time Series: League Policy Lessons," in The Econometrics of Sports, edited by P. Rodriguez, S. Kesenne, and J. Garcia. Cheltenham: Edward Elgar.

Fort, R., and J. Quirk. "Cross-Subsidization, Incentives, and Outcomes in Professional Team Sports Leagues." Journal of Economic Literature, 23, 1995, 1265-99.

Gitter, S. R., and T. A. Rhoads. "Determinants of Minor League Baseball Attendance." Journal of Sports Economics, 12, 2011, 341-51.

Hadley, L., J. Ciecka, and A. Krautmann. "Competitive Balance in the Aftermath of 1994 Players' Strike." Journal of Sports Economics, 2005, 6, 379-89.

Hockey-Reference. "NHL Season Summary." 2012. Accessed November 6, 2012. http://www.hockeyreference.com/leagues/NHL_2010.html.

Hockey Zone Plus. "Attendances Per League, Per Season." 2010. Accessed March 20, 2010. http://www.hockey zoneplus.com/attend.htm.

Humphreys, B. R. "Alternative Measures of Competitive Balance in Sports Leagues." Journal of Sports Economics, 3, 2002, 133-48.

Jones, J. C. H., and D. G. Ferguson. "Location and Survival in the National Hockey League." Journal of Industrial Economics, 36, 1988, 443-57.

Kahane, L., and S. Shmanske. "Team Roster Turnover and Attendance in Major League Baseball." Applied Economics, 29, 1997, 425-31.

Knowles, G., K. Sherony, and M. Haupert. "The Demand for Major League Baseball: A Test of the Uncertainty of Outcome Hypothesis." American Economist, 36, 1992, 72-80.

Krautmann, A. C., and L. Hadley. "Dynasties Versus Pennant Races: Competitive Balance in Major League Baseball." Managerial and Decision Economics, 27, 2006, 287-92.

Krautmann, A., Y. H. Lee, and K. Quinn. "Playoff Uncertainty and Pennant Races." Journal of Sports Economics, 12, 2011, 495-514.

Kurtzberg, B. "The NHL's First All-California Playoff." Inside Hockey, 2009. Accessed May 2009. http://insidehockey.com/?p=3549.

Leadley, J. C., and Z. X. Zygmont. "When Is the Honeymoon Over? National Hockey League Attendance 1970-2003." Canadian Public Policy, 32, 2006, 213-32.

Lee, J., and M. C. Strazicich. "Break Point Estimation and Spurious Rejections with Endogenous Unit Root Tests." Oxford Bulletin of Economics and Statistics, 63, 2001, 535-58

. "Minimum LM Unit Root Test with Two Structural Breaks." Review of Economics and Statistics, 85, 2003, $1082-89$.

_. "Minimum LM Unit Root Test with One Structural Break." Working Paper, Department of Economics, Appalachian State University, 2004.

Lee, Y. H. "The Impact of Postseason Restructuring on the Competitive Balance and Fan Demand in Major League Baseball." Journal of Sports Economics, 10, 2009, 219-35.

Lee, Y. H., and R. Fort. "Attendance and the Uncertaintyof-Outcome Hypothesis in Baseball." Review of Industrial Organization, 33, 2008, 281-95.

Lemke, R. J., M. Tlhokwane, and K. Leonard. "Estimating Attendance at Major League Baseball Games for the 
2007 Season.” Journal of Sports Economics, 2007, 11, 316-48.

Lenten, L. "Towards a New Dynamic Measure of Competitive Balance: A Study Applied to Australia's Two Major Professional Football Leagues." Economic Analysis \& Policy, 39, 2009, 407-28.

Leybourne, S. J., T. C. Mills, and P. Newbold. "Spurious Rejections by Dickey-Fuller Tests in the Presence of a Break Under the Null." Journal of Econometrics, 87, 1998, 191-203.

Meehan, J. W., R. A. Nelson, and T. V. Richardson. "Competitive Balance and Game Attendance in Major League Baseball." Journal of Sports Economics, 8, 2007, 563-80.

Newey, W., and K. West. "Automatic Lag Selection in Covariance Matrix Estimation." Review of Economic Studies, 61, 1994, 631-53.

Noll, R. G. "Attendance and Price Setting," in Government and the Sports Business, edited by R. G. Noll. Washington, DC: Brookings Institution, 1974.

_. Professional Basketball (Studies in Industrial Economics Paper No. 144). Stanford, CA: Stanford University, 1988.

Owen, P. D. "Limitations of the Relative Standard Deviation of Win Percentages for Measuring Competitive Balance in Sports Leagues." Economics Letters, 109, 2010, 38-41.

. "Measuring Parity in Sports Leagues with Draws: Further Comments." Journal of Sports Economics, 13, 2012, 85-95.

Paul, R. "Variations in NHL Attendance: The Impact of Violence, Scoring and Regional Rivalries." Journal of Economics and Sociology, 62, 2003, 345-64.

Paul, R. J., and A. P. Weinbach. "The Uncertainty of Outcome and Scoring Effects on Nielsen Ratings for Monday Night Football." Journal of Economics and Business, 59, 2007, 199-211.

Perron, P. "The Great Crash, the Oil Price Shock, and the Unit Root Hypothesis." Econometrica, 57, 1989, $1361-401$.

Pivovarnik, T., R. Lamb, R. Zuber, and J. Gandar. "Competitive Balance and Fan Interest in the National Football League." Journal of Economics and Economic Education Research, 9, 2008, 75-98.

Pro-Football-Reference. "Standings, Teams \& Offensive Stats.” 2012. Accessed November 6, 2012. http://www.pro-football-reference.com/years/2010/.

Rascher, D. A., and J. P. G. Solmes. "Do Fans Want Close Contests? A Test of the Uncertainty of Outcome Hypothesis in the National Basketball Association." International Journal of Sport Finance, 2, 2007, $130-41$
Rod's Sports Business Data. "National Basketball Association: Attendance." 2012a. Accessed November 6, 2012. https://umich.box.com/files/0/f/320022885/NBA Attendance.

. "National Football League: Attendance." 2012b. Accessed November 6, 2012. https://umich.box.com/ files/0/f/320026115/NFLAttendance.

- "National Hockey League: Attendance." 2012c. Accessed November 6, 2012. https://umich.box.com/ files/0/f/320029199/NHLAttendance.

Rottenberg, S. "The Baseball Players' Labor Market." Journal of Political Economy, 64, 1956, 242-58.

Schmidt, M. B., and D. J. Berri. "Competitive Balance and Attendance: The Case of Major League Baseball." Journal of Sports Economics, 2, 2001, 145-67.

- "The Impact of the 1981 and 1994-1995 Strikes on Major League Baseball Attendance: A Time-Series Analysis." Applied Economics, 34, 2002, 471-78.

. "The Impact of Labor Strikes on Consumer Demand: An Application to Professional Sports." American Economic Review, 94, 2004, 334-47.

Scully, G. W. The Business of Major League Baseball, Chicago: University of Chicago Press, 1989.

Siegfried, J. J., and J. D. Eisenberg. "The Demand for Minor League Baseball." Atlantic Economic Journal, 8I, 1980, 59-69.

Soebbing, B. P. "Competitive Balance and Attendance in Major League Baseball: An Empirical Test of the Uncertainty of Outcome Hypothesis." International Journal of Sport Finance, 3, 2008, 119-26.

Szymanski, S. "The Economic Design of Sporting Contests." Journal of Economic Literature, 41, 2003, 1137-87.

Tainsky, S., and J. A. Winfree. "Short-run Demand and Uncertainty of Outcome in Major League Baseball." Review of Industrial Organization, 37, 2010a, 197-214.

. "Discrimination and Demand: The Effect of International Players on Attendance in Major League Baseball." Social Science Quarterly, 91, 2010b, 117-28.

Winfree, J. A., and R. Fort. "Fan Substitution and the 200405 NHL Lockout." Journal of Sports Economics, 9, 2008, 425-34.

Winfree, J. A., J. J. McCluskey, R. C. Mittelhammer, and R. Fort. "Location and Attendance in Major League Baseball." Applied Economics, 36, 2004, 2117-24.

Zivot, E., and D. W. K. Andrews. "Further Evidence on the Great Crash, the Oil Price Shock, and the Unit Root Hypothesis." Journal of Business and Economic Statistics, 10, 1992, 251-70. 